\title{
Motivating Low-Achieving Learners to Use Mobile Assistive Courseware through Signaling Principle
}

\author{
https://doi.org/10.3991/ijim.v13i04.10527 \\ A.M. Ariffin $(\bowtie)$ \\ Universiti Utara Malaysia, Sintok, Kedah, Malaysia \\ am.ariffin@uum.edu.my \\ A.Siti Zulaiha \\ Universiti Teknologi MARA, Arau, Perlis \\ S. Ahmad Jelani \\ Universiti Utara Malaysia, Sintok, Kedah, Malaysia
}

\begin{abstract}
Developing a courseware is easy. However, making a courseware usable for its target user requires a scientific process. As a response to that, a study has been carried out in making courseware usable for lowachieving learners. As part of the study, this paper aims to describe the application of signaling principles in the developed courseware specifically for low-achieving learners. The prototype has been developed through usercentered approach. It involved users during the designing and development process. Then, it was delivered to users. Their experience dealing with the developed prototype was observed in their natural context with assistance of their teachers. Eventually, it was found that they were highly motivated to use the courseware.
\end{abstract}

Keywords - Signaling principles, low-achieving learners, usability, interaction design, assistive courseware.

\section{Introduction}

Human-Computer Interaction (HCI) is a discipline that highly considers the usability of interactive computer system involving users in various domains who require technology to accomplish their activities [1,2]. It is purely related to three main concerns, which are: i) the people (users), ii) the technology (system) and iii) activities (interactivities). The evolution of interactive productsincluding computer assisted learning (CAL) offers a bright concept of interaction design. Accordingly, an interactive CAL application must consider an effective user interface design $[3,20,21]$, in which interaction concept act as part of its elements [4]. With a good interaction concept, interactive CAL or courseware will reach its ultimate goal as a usable application [5,6,23]. In contrast, the lacking of an appropriate design concept leads to inefficiency of user-courseware interaction $[7,8,24]$, especially in the low 
achieving (LA) children learning environment.Problems encountered by the LA children require further investigation on the interaction component of a CAL [9].

Not only the components are important, but the design needs to notify users on their tasks [25,26]. This could ensure users' mental effort is not burdened unnecessarily, especially the users in this study (the low-achieving learners) are associated with weak mental processing [10]. To handle this, this study incorporates signaling principle into its design. The signaling principle has been recommended as part of multimedia design principle [30]. Hence, it has been applied in designing interactive products. However, its application in products for low-achieving learners has not been found in the literature. Hence, this study intends to prove that signaling principle is able to support user's motivation in using the assistive courseware. For the purpose of this study, the content for the assistive courseware is mathematics. It has been decided through a survey carried out among teachers in schools (the schools involve directly in this study). Accordingly, the assistive courseware is called iCAL4LA-Bijak Matematik.

Based on the above, this paper aims to report the application of signaling principle in the iCAL4LA-Bijak Matematik. As a consequence, the impact of the signaling principle on learners' motivation is observed. While this section sets the background for this paper, the following section reviews the signaling principle, followed with the method, which details the process having gone through. Further, the results are addressed and discussed, before the whole paper is concluded.

\section{Method}

This study involves three steps of research activities, which are selection of the component, design and develop of the courseware, and testing of user experience. First, this study determines and selects the component for the iCAL4LA-Bijak Matematik. Next, during the design and development process, this study integrates the selected techniques into the iCAL4LA-Bijak Matematik. Based on the outcome of the previous process, iCAL4LA-Bijak Matematik undergo user experience testing in investigating the motivating aspect. In order to gather the user motivating aspect, this study utilizes interaction log using specialize software, Free Studio that provides a screen video recording while the user interacting with the prototype. Using the software, the recorded video can be stored and retrieved later for analysis purposes. Finally, this study analyzes the results and justifies them based on the ability of the LA children in accomplishing the whole content of iCAL4LA-Bijak Matematik. Figure1 summarizes the whole process of this study.

\subsection{Selection of appropriate signaling cues for iCAL4LA-Bijak Matematik}

This step involves two tasks; identifying signaling principles for the low-achieving learners, and selecting appropriate signaling cues for the iCAL4LA-Bijak Matematik. The identifying signaling principles were done together with the users (the learners). They were involved because input from them is paramount for this study, in which 
what signals them have some differences than that for normal learners. So, everything that could signal them were considered and put in a list.

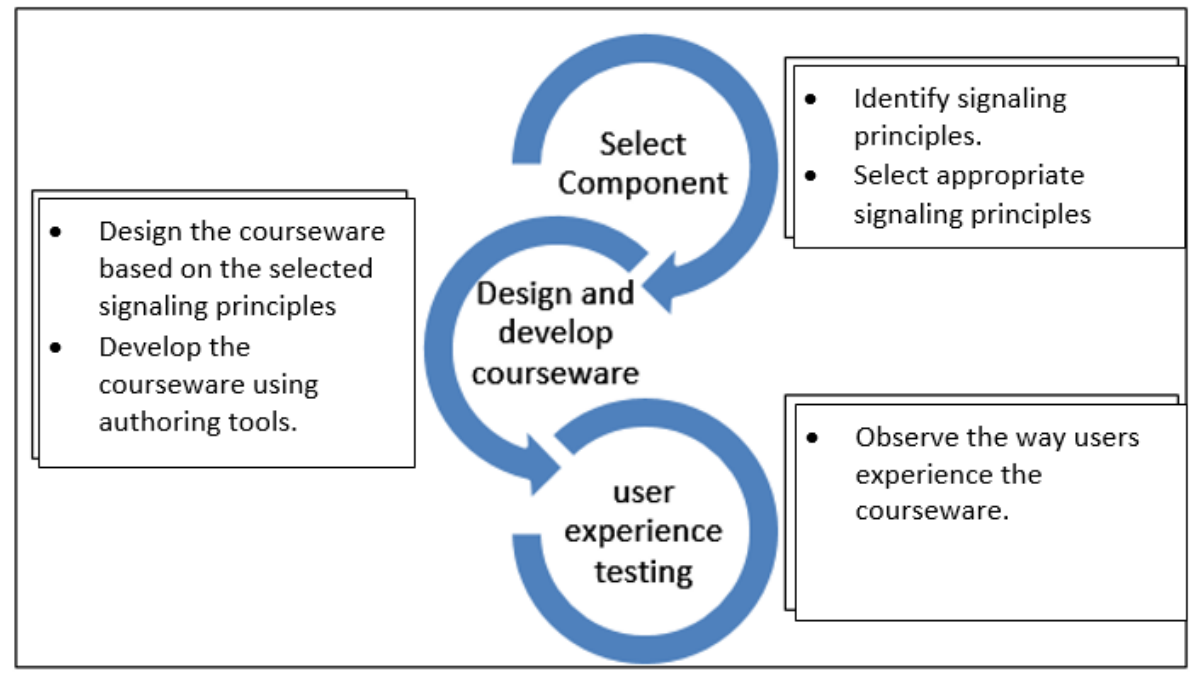

Fig. 1. The research methods

Then, from the identified principles, the most appropriate signaling cues for iCAL4LA-Bijak Matematik were determined. This was done through a workshop, in which five digital storybooks were used as the apparatus. The digital storybooks contains various signaling cues. Through the workshop, a list of appropriate signaling cue for iCAL4LA-Bijak Matematik was obtained. The following section details the signaling cues applied in the assistive courseware for the low-achieving learners.

\subsection{Design and development of the iCAL4LA-Bijak Matematik}

The main concern of this paper is to demonstrate the way the iCAL4LA-Bijak Matematik incorporates signaling principles in ensuring learners have positive experience. Hence, this section describes about the signaling principles being applied in its design. The designing process involved the actual users, similar group of learners involved in determining the signaling cues. This approach is known as usercentered design, which takes advantage of user direct involvement in giving feedback on the design. In this study, the designing work began with storyboarding (example of a page is seen in Figure 2). Through the storyboarding, users express their understanding, and this study take appropriate actions accordingly.

Then, based on the agreed storyboard, the design was transferred into a working courseware. The snapshots of the iCAL4LA-Bijak Matematik are seen in Figure 3 through 6. In Figure 3, the assistive courseware is equipped with signaling through the use of place holder. Through the place holder, users are confident that they are clickable buttons. The signal is enhanced because the buttons visually reflect on 
mouse over. Besides, the use of color notifies different roles of the text/numbers. It is also used to signal the active tab. Such notification is also workable through the use of size and outline. Meanwhile, the use of arrow sign is strong in leading users' attention, so that they follow the points of discussion.

\begin{tabular}{|l|l|}
\hline Title screen: Addition Operation & Bagus, adik sungguh bersemangat nak belajar. \\
\hline Storyboard & Adik boleh lihat contoh tambah 1, 2 atau 3. \\
\hline
\end{tabular}

Fig. 2. Sample of storyboard

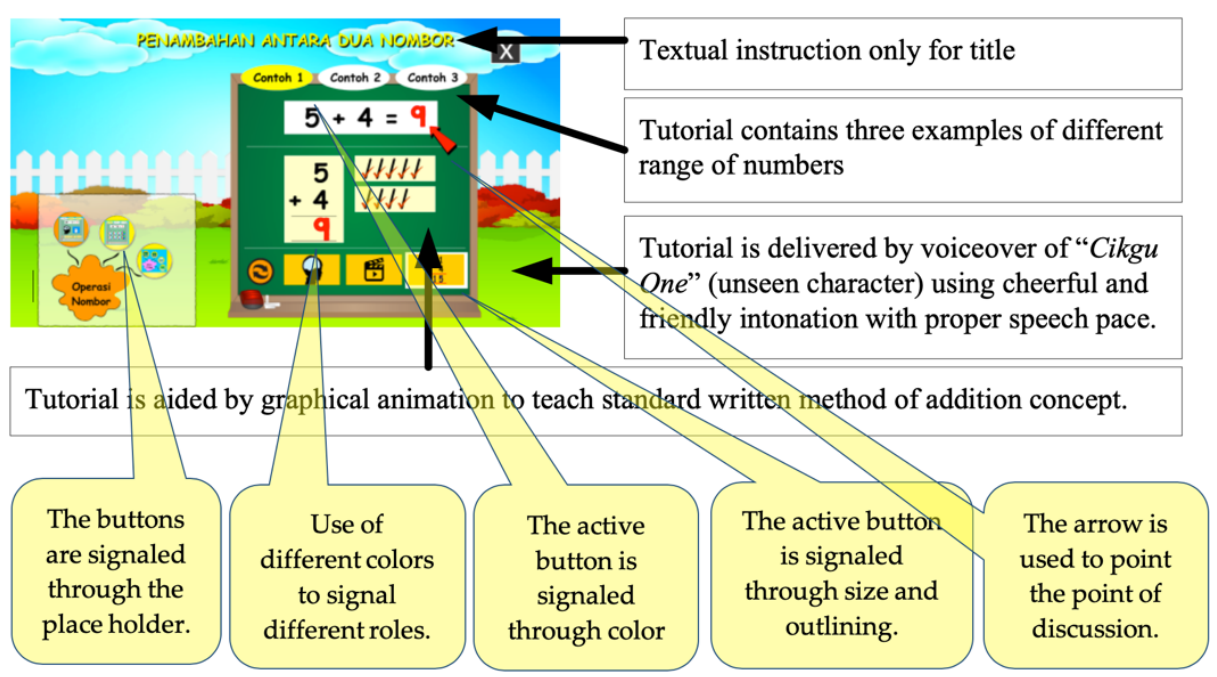

Fig. 3. Signaling through place holder, color, size, outline, and arrow sign 
The use of the cues in Figure 3 is highly recommended by previous studies [31-39]. Similar studies also applied the cues shown in Figure 4.

Figure 4 shows two snapshots of the iCAL4LA-Bijak Matematik that contains significant signaling cues for the low-achieving learners. Signaling through the use of different colors is applied in differentiating groups. Also, it is used in contrasting different syllables in sentences. This enhances learners reading ability, which is important in supporting the variation in learning techniques. iCAL4LABijakMatematik provides the list of answer options in vertical order. This more strongly notifies that they are individual numbers as compared to horizontal list $[28,29]$. Another signal in the figure is in the arrangement of the answer place holders. It is seen that they are mapped with the questions, so that the users could easily associate the boxes for questions and answers.

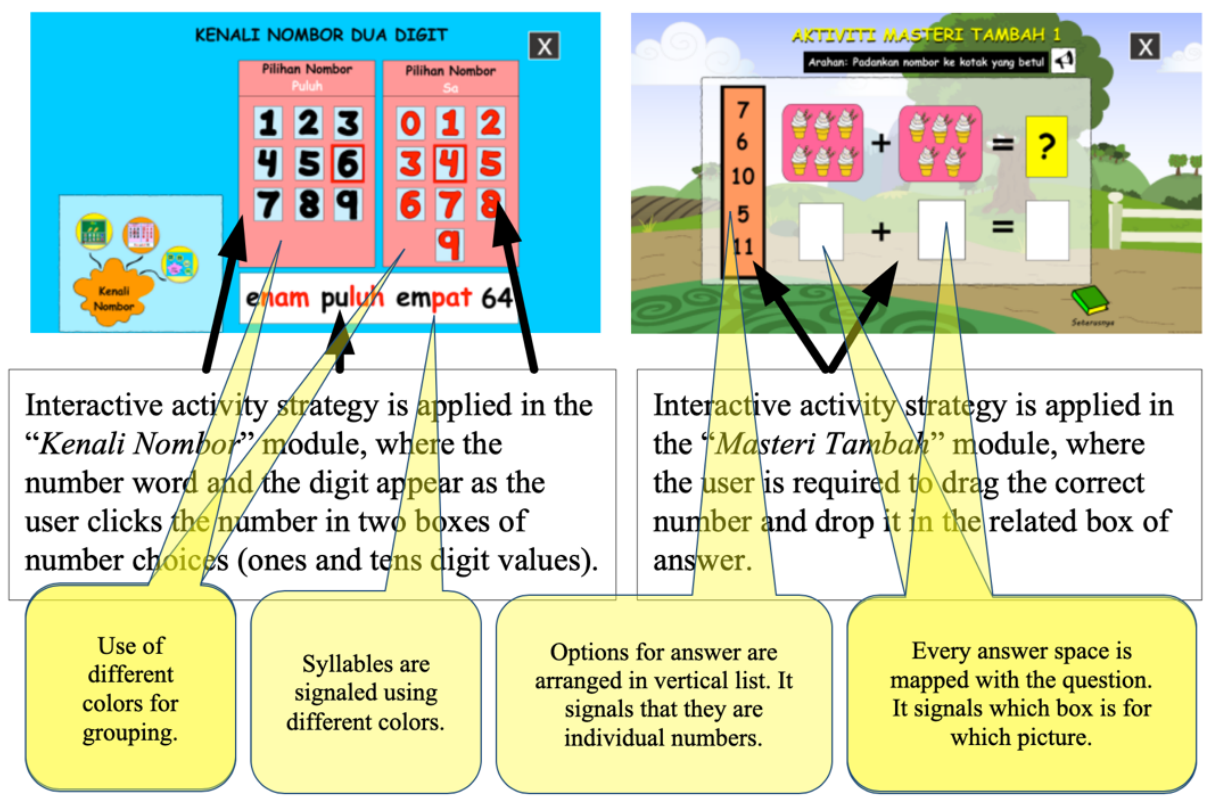

Fig. 4. Signaling through color differentiation, item arrangement, and mapping

In Figure 5, the slider is used to signal the remaining time of the video. It also makes use of color, size, and outline to notify the active tabs. When users are supported with such signals, they do not have to guess or make assumption, but they are always sure about the current state of the video content. It also allows users to slide to any exact location they want to jump to.

Meanwhile, Figure 6 depicts the use of metaphor and audio as signaling techniques. The use of metaphor enables users to recognize its function, rather than having to guess. In this kind of product, guessing is an excise, which increases cognitive load unnecessarily. Hence, when users are signaled and their cognitive load reduced, they could focus on the content. Audio is used to strengthen users' 
confidence, because it amplifies what they see. It is also a strong signaling technique so that users feel more alert.

\subsection{User Experience Testing of iCAL4LA-Bijak Matematik}

There were 30 subjects involved in the user experience testing. The subjects were selected by the LINUS teachers, who coordinate the screening program in school. They were also verified as LA children based on their academic performance in the most recent test (for year 1 children) including the previous year of the final examination results. The permission to involve the subjects in this study was obtained from their guardians using an agreement form witnessed by their class teacher.

Data were gathered through observation. For the purpose of reference, the user experience session was video recorded. During the session, each user was provided with a PC installed with the iCAL4LA-Bijak Matematik. Users were encouraged to maneuver the assistive courseware on their own convenience, but within the given time. They were given 45 minutes to play around with the courseware. The allocated time is more than enough for them to explore the whole content in the courseware.

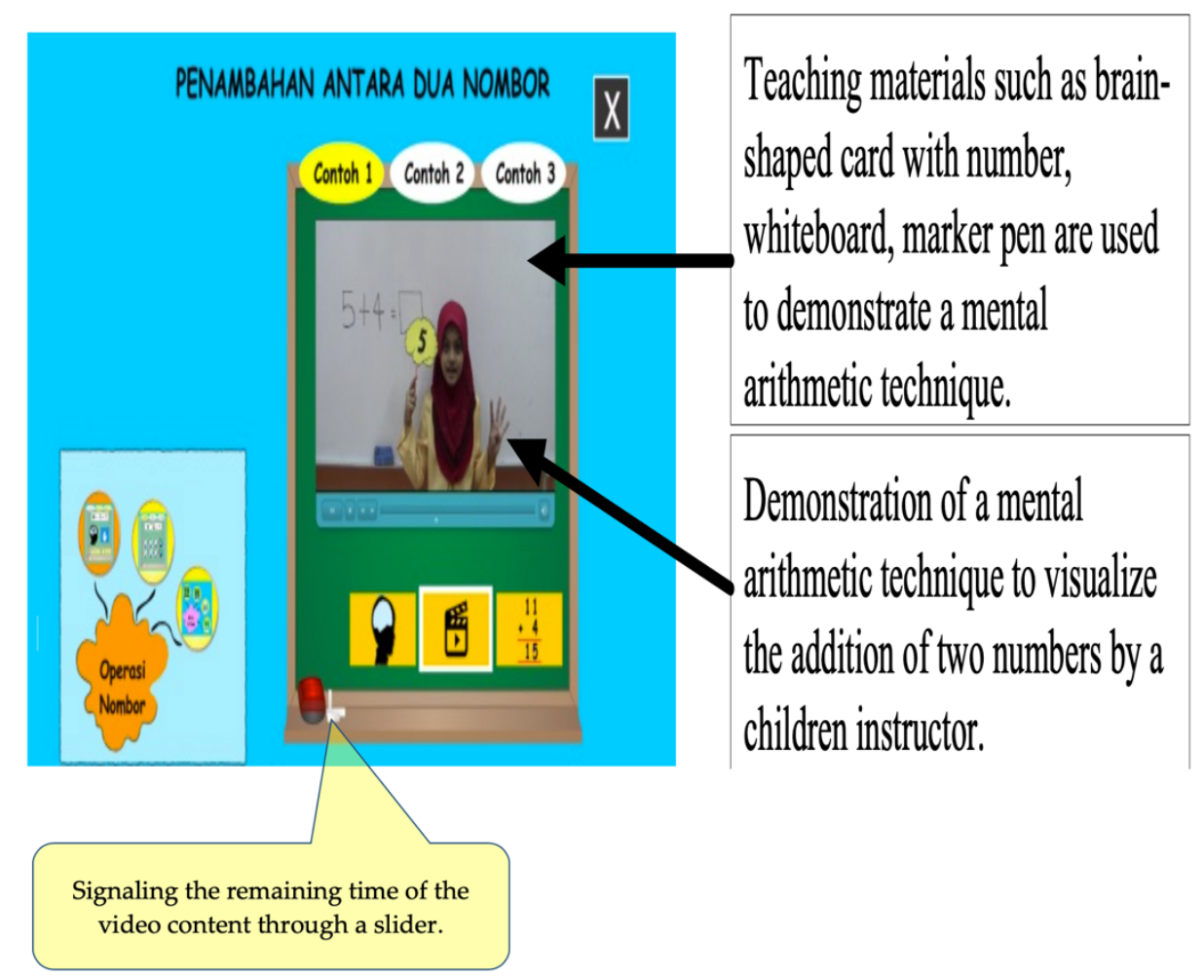

Fig. 5. Signaling through the slider 


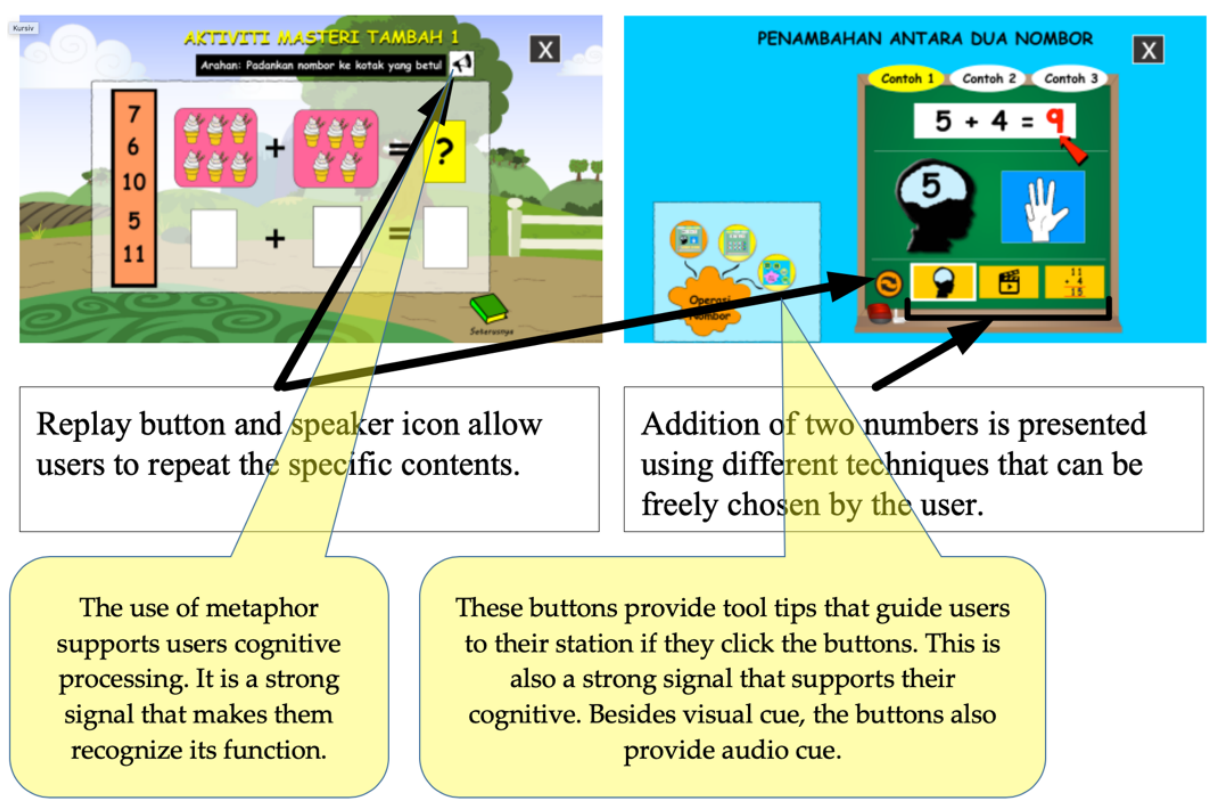

Fig. 6. Signaling through metaphor and audio cue

\section{$3 \quad$ Result and Discussion}

The motivation aspect was observed through users' behavior and attitude while interacting with the iCAL4LA-Bijak Matematik. At the same time their interaction with the courseware was logged. However, this paper discusses the results gained from observation only.

During the user experience session, the users were found very actively communicating with their PC, or more precisely with the iCAL4LA-Bijak Matematik. They sang together with the courseware at the beginning of the session, and clapping their hands together. At the same time they interacted with their peers. Throughout the session, only two learners gave-in, and did not finish learning the whole content. Meanwhile, the other 28 learners finish the learning tasks confidently. It was so interesting to see that the learners kept chasing among each other, in interactive with the courseware. When the allocated time was over, they refused to stop interacting with the courseware, in contrast they asked for another 10 minutes for them to finish doing their tasks.

Along the process, they were seen clicking the courseware on their own, without asking many questions to their teachers. When the courseware speaks, they speak together with the courseware. When a learner realized a peer resisted, the learner just gave a simple instruction that the peer could already make it. This attitude and behavior were seen taking place throughout the session. Although there were some discouraging symptoms seen throughout the session, like asking questions, writhing, nodding, and the like, this study believes the symptoms are normal. They also appear 
in any situation, in which for this study they do not distort the impact of the designed assistive courseware.

For this study, such behavior and attitude are driven by the interface, which is specifically design for them, with their direct input through the user-centered design approach $[14,17]$. As addressed in the early part of this paper, the use of signaling principle could enhance the low-achieving learners' engagement with the learning material. This study makes the interface as easy as possible for them, in which standardization is paramount [19]. This is important to support their recognition, hence reducing their mental efforts $[12,13]$. The incorporation of signaling cues demonstrated in the previous section is applied throughout the iCAL4LA-Bijak Matematik.

\section{Conclusion}

Based on the observation, this study believes that the signaling principle through the place holder, color, size, outline, mapping, metaphor, item arrangements, and audio cues motivates the learners in interacting with theiCAL4LA-Bijak Matematik. It is important to keep the interface very straight forward for the low-achieving learners $[1,5,14]$, but at the same time the aesthetical aspect must be considered [18,22,27]. On top of all design strategies, ensuring standardization throughout the learning material is paramount. Nevertheless, as they are born with special characteristics, interactive learning materials for them need special design $[8,9,11]$, hence their direct input during the design process is strongly necessary $[6,7,16]$.

Based on the findings, this study recommends that the impact of other multimedia principles over the low-achieving learners, not only signaling principle, should be further studied. It has been generally understood that multimedia principles impact the users, perhaps the impact over the special groups of users are wilder.

\section{Acknowledgement}

We thank to the Ministry of Higher Education for granting this research under FRGS scheme. The research could be identified through the S/O Code 13574.

\section{References}

[1] A. Dix, J. Finlay, G. D. Abowd, and R. Beale, Human computer interaction, Third Edit. England: Pearson Educ. Limited, 2004.

[2] R. L. Yussof and H. Badioze Zaman, Usability evaluation of multimedia courseware (MEL-SindD), Lect. Notes Comput. Sci. (including Subser. Lect. Notes Artif. Intell. Lect. Notes Bioinformatics), vol. 5857 LNCS, pp. 337-343, 2009.

[3] Y. M. Huang, T. H. Liang, Y. N. Su, and N. S. Chen, Empowering personalized learning with an interactive e-book learning system for elementary school student," Educ. Technol. Res. Dev., vol. 60, no. 4, pp. 703-722, 2012. https://doi.org/10.1007/s11423-012-9237-6 
[4] D. Churchill, Presentation design for 'conceptual model' learning objects, Br. J. Educ. Technol., vol. 45, no. 1, pp. 136-148, 2014. https://doi.org/10.1111/bjet.12005

[5] C. Chou, Interactivity and interactive functions in web-based learning systems: A technical framework for designers, Br. J. Educ. Technol., vol. 34, no. 3, pp. 265-279, 2003. https://doi.org/10.1111/1467-8535.00326

[6] J. P. Hourcade, Interaction design and children, Found. Trends Human-Computer Interact., vol. 1, no. 4, pp. 277-392, 2007. https://doi.org/10.1561/1100000006

[7] J. C. Read and P. Markopoulos, Child-computer interaction, Int. J. Child-Computer Interact., vol. 1, no. 1, pp. 2-6, Jan. 2013. https://doi.org/10.1016/j.ijcci.2012.09.001

[8] W. A. Wan Fatimah, M. N. Shahrina, and M. S. Nor Syafiza, Development of a multimedia courseware for slow learner children with reading difficulties: MyLINUS, in Lecture Notes in Computer Science, 2013, vol. 8237, pp. 371-382. https://doi.org/10.1 007/978-3-319-02958-0_34

[9] A. SitiZulaiha and A. M. Ariffin, Preliminary study: An investigation on learning assistance requirement among low achievers in primary schools, Int. J. Comput. Appl., vol. 114, no. 2, pp. 48-54, 2015.

[10] A. SitiZulaiha and A. M. Ariffin, Exploring computer assisted learning for low achieving children: A comparative analysis study, J. Teknol., vol. 77, no. 29, pp. 1-7, 2015.

[11] B. Shneiderman and C. Plaisant, Designing the user interface: Strategies for effective human-computer interaction, 4th ed. USA: Pearson Edu., Inc, 2005.

[12] M. S. MohdAzrul, The impact of interactivity features in enhancing online communication satisfaction, Malaysian J. Coomunication, vol. 28, no. 2, pp. 21-36, 2012.

[13] J. Sweller, Cognitive load theory, learning difficulty, and instructional design, Learn. Instr., vol. 4, no. 4, pp. 295-312, 1994. https://doi.org/10.1016/0959-4752(94)90003-5

[14] R. Moreno and R. Mayer, Interactive multimodal learning environments, Educ. Psychol. Rev., vol. 19, no. 3, pp. 309-326, Jun. 2007. https://doi.org/10.1007/s10648-007-9047-2

[15] D. Fallman, The Interaction design research triangle of design practice, design studies, and design exploration, Des. Issues, vol. 24, no. 3, pp. 4-18, Jul. 2008. https://doi.org/10 $.1162 /$ desi.2008.24.3.4

[16] Y. Rogers, H. Sharp, and J. Preece, Interaction Design: Beyond Human - Computer Interaction, vol. 6. John Wiley \& Sons, 2011.

[17] E. Goodman, E. Stolterman, and R. Wakkary, Understanding interaction design practices, in Proceedings of the SIGCHI Conference on Human Factors in Computing Systems, 2011.

[18] A. Cooper, R. Reimann, and D. Cronin, About Face 3.0: The essentials of interaction design, vol. 3. 2007.

[19] P. Markopoulos and M. Bekker, Interaction design and children, Interact. Comput., vol. 15, no. 2003, pp. 141-149, 2003.

[20] R. Molich and D.-Ballerup, Heuristic evaluation of userfaces, in CHI '90 Proceedings, 1990, no. April, pp. 249-256.

[21] R. E. Mayer, Multimedia learning, 2nd ed. Cambridge University Press, 2009. https://doi.org/10.1017/CBO9780511811678

[22] D. J. Mayhew, Principles and guidelines in software user interface design. Prentice-Hall, Inc., 1991.

[23] R. Y. Shimabukuro, Designing an interactive spoken help application for preschool children, in Proceedings of the 7th International Conference on Interaction Design and Children - IDC '08, 2008, pp. 149-152. 
[24] W. A. J. Wan Yahya and S. N. Abdul Salam, Usability design strategies for children: Developing children learning and knowledge in decreasing children dental anxiety, in International Conference of Primary Education 2009, 2009, pp. 1-15.

[25] S. H. Lee and E. Boling, Screen design guidelines for motivation in interactive multimedia instruction: A survey and framework for designers, Educ. Technol., vol. 39, no. 3, pp. 1926, 1999.

[26] A. M. Ariffin, Conceptual design of Reality Learning Media (RLM) model based on entertaining and fun constructs, Universiti Utara Malaysia, 2009.

[27] B. Shneiderman, Designing for fun: How can we design user interfaces to be more fun, Interactions, vol. 11, no. 5, p. 48, 2004. https://doi.org/10.1145/1015530.1015552

[28] Jobst, J \& Dillon A. (2014). Multimedia learning in hypermedia. In R. E. Mayer (Ed.), The Cambridge handbook of multimedia learning. New York: Cambridge University Press.

[29] Mautone, P. D. \& Mayer, R. E. (2001). Signaling as a cognitive guide in multimedia learning. Journal of Educational Psychology. 93. 377-389. https://doi.org/10.1037/00220663.93.2.377

[30] Mayer, R. E. (2009). Multimedia learning (2nd ed). New York: Cambridge University Press. https://doi.org/10.1017/CBO9780511811678

[31] Mayer, R. E. (2011). Applying the science of learning. Upper Saddle River, NJ: Pearson.

[32] Mayer, R. E. (2014). Principles based on social cues: Personalization, voice, image, and embodiment principles. In R. E. Mayer (Ed.), The Cambridge handbook of multimedia learning. New York: Cambridge University Press. https://doi.org/10.1 $\underline{017 / \mathrm{CBO} 9781139547369.017}$

[33] Mayer, R. E.,\&Fiorella, L. (2014). Principles for reducing extraneous processing in multimedia learning: Coherence, signaling, redundancy, spatial contiguity, and temporal contiguity principles. In R. E. Mayer (Ed.), The Cambridge handbook of multimedia learning. New York: Cambridge University Press. https://doi.org/10.1 017/CBO9781139547369.015

[34] Mayer, R. E., \&DaPra, C. S. (2012). An embodiment effect in computer-based learning with animated pedagogical agent. Journal of Experimental Psychology: Applied, 18, 239252. https://doi.org/10.1037/a0028616

[35] Mayer, R. E., Heiser, H., \&Lonn, S. (2001). Cognitive constraints on multimedia learning: When presenting more material results in less understanding. Journal of Educational Psychology, 93, 187-198. https://doi.org/10.1037/0022-0663.93.1.187

[36] Ash, I.K. \& Wiley, J. (2014). Multimedia learning of History. In R. E. Mayer (Ed.), The Cambridge handbook of multimedia learning. New York: Cambridge University Press.

[37] Atkinson, R.K. (2014). Multimedia learning of Mathematics. In R. E. Mayer (Ed.), The Cambridge handbook of multimedia learning. New York: Cambridge University Press.

[38] Butcher, K. (2014). The multimedia principle in multimedia learning. In R. E. Mayer (Ed.), The Cambridge handbook of multimedia learning. New York: Cambridge University Press. https://doi.org/10.1017/CBO9781139547369.010

[39] Clark, R.C. (2014). Multimedia Principles in e-Courses. In R. E. Mayer (Ed.), The Cambridge handbook of multimedia learning. New York: Cambridge University Press. https://doi.org/10.1017/CBO9781139547369.040

[40] Wan Ahmad Jaafar, W. Y., \&Awaatif A. (2017). The effectiveness of signaling principle in virtual reality courseware towards achievement of transfer learning among students with different spatial ability.In AIP Conference Proceedings. 1891, 020144 (2017) https://doi.org/10.1063/1.5005477 
[41] Derlina, Dalle, J., Hadi, S., Abdul Mutalib, A., Sumantri, C. (2018). Signaling principles in interactive learning media through expert's walkthrough.Turkish Online Journal of Distance Education19 (4), pp. 147-162. https://doi.org/10.17718/tojde.471911

[42] Yusrita, M.Y., Ariffin, A.M., Ying, G.S., Zing, G.H. (2018). Non-applying signaling principles increases excise and memory load in interactive learning material. Journal of Advanced Research in Dynamical and Control Systems.10(10 Special Issue), pp. 15401547

\section{$7 \quad$ Authors}

Ariffin Abdul Mutalibis an Associate Professor at the Institute of Creative Humanities, Multimedia, and Innovation, School of Multimedia Technology and Communication, Universiti Utara Malaysia. He is a research fellow at Institute of Creative Humanities, Multimedia, and Innovation. His current research interests include Human-computer Interaction, Usability, and Computers in teaching and learning. He also serves as a permanent reviewer for various international conferences.

SitiZulaiha is the Senior Lecturer of Computer Science for Faculty of Computer Science and Mathematical Sciences, Universiti Teknologi MARA Perlis Branch. She has experience in teaching various subjects related to Information System, Database System, Software Engineering and Structured Programming languages. In research, SitiZulaiha focuses in Human Computer Interaction, Interaction Design, Multimedia Technology, and User Experience and contributes her expertise in education and geographical information system research teams.

Ahmad Jelani B Shaari is an Assoc. Prof at the school Education and Modern Language, Universiti Utara Malaysia. His current research interests are in the area of audit and corporate governance. He is expertised in ICT in Education, Instructional Technology Planning \& Management and E-Learning.

Article submitted 2019-01-11. Resubmitted 2019-03-03. Final acceptance 2019-03-10. Final version published as submitted by the authors. 